\title{
A CLINICAL STUDY OF THE TREATMENT OF ROOT CANAL AND PERIAPICAL INFECTIONS WITH PENICILLIN ${ }^{1}$
}

\author{
FLOYD D. OSTRANDER, D.D.S., M.S., MARY C. CROWLEY, M.S.P.H., \\ AND JOHN DOWSON, D.D.S., M.S. \\ University of Michigan, School of Dentistry, Ann Arbor,.Mich.
}

In the past two years a number of reports on the use of penicillin in the treatment of root canal and periapical infections have appeared in the literature (1-9). While most of the reports have indicated favorable results, there has been considerable variation in the degree of success and some of the reports have been inconclusive because of incomplete bacteriological controls.

\section{PROCEDURE}

Some preliminary clinical work was done at Michigan in which penicillin was used in the treatment of infected root canals, first in solution in physiological salt solution (5000 u. per c.c.) and later by use of absorbent points which had been saturated with $1000 \mathrm{u}$. of penicillin each. Results in a small series were unsatisfactory as compared to results obtained with commonly used drugs. Therefore, it was felt that if penicillin were to be used successfully some method must be found by which a large quantity of penicillin could be used in the tooth in a form that would slowly release penicillin over an extended period.

After some study it was found that by using a paste made up with penicillin, calcium carbonate and physiological salt solution it was possible to incorporate from 5000 to 10,000 units in the average root canal and pulp chamber and that the penicillin was slowly released over a period ranging up to 96 hours. This was confirmed by recovering absorbent points from penicillin-treated root canals after $24,48,72$ and 96 hour intervals. These points were then placed in 5\% blood agar plates with beef infusion broth base inoculated with a culture of Streptococcus dysgalactiae, an organism extremely sensitive to penicillin, as determined by Kakavas and Scott (10). After incubation for 48 hours it was found that all points showed significant areas of inhibited growth in the agar, thus indicating that effective quantities of penicillin were present up to 96 hours.

The clinical phase of this study was carried out by treatment of root canal cases in the clinic by exactly the same procedure as that routinely used, except for the substitution of penicillin for camphorated p. monochlorophenol or other commonly used drugs. Special precaution was taken to completely dry the canals of solution of sodium hypochlorite which is routinely used at each appointment for washing the root canals, since it would tend to inactivate the penicillin.

1 Read at the 25th General meeting of the International Association for Dental Research, Chicago, June 21-22, 1947. (J.D. Res. 26:456, 1947). Received for publication July 9, 1947. 
All work was done under rigidly aseptic conditions and cultures were taken in a beef infusion semi-solid medium with ascitic fluid immediately after opening the tooth and at each succeeding treatment, usually at 48 hour intervals. In those cases in which penicillin was used a duplicate culture was taken in the same medium to which 100 Schenley units of penicillinase per c.c. of medium had been added. This was done to eliminate the possibility that sufficient penicillin might be carried over from the tooth to the culture media to inhibit the growth of organisms.

Since it was felt that some of the variation in results reported from the use of penicillin in root canal therapy might well be due to the presence of resistant organisms in some teeth, a concurrent laboratory study of the penicillin sensitivity of the organisms isolated from the root canals was carried out. ${ }^{2}$

\section{RESULTS}

The results of this study are summarized in Tables I to V. In Table I it will be noted that 79 cases were treated with penicillin and of these $29(36.7 \%)$ were sterile from the start and obviously gave no information as to penicillin effectiveness. In some previously reported studies it has been assumed that all cases were infected and initial cultures were not taken. This would obviously give an unduly favorable picture of the effectiveness of penicillin since several series of root canal cases studied at the University of Michigan have always shown from 35 to $50 \%$ of the cases to be non-infected, depending on the type of cases being studied.

Another group of 16 cases had to be eliminated from statistical consideration because they were accidentally contaminated, i.e., crown forms came off, cement fillings came out and in 2 instances acute exacerbations occurred which necessitated opening the tooth for drainage.

This left a group of 34 cases which were statistically significant. Of these, 20 responded to penicillin therapy with an average of 3.55 treatments to obtain 2 negative cultures while 14 did not respond to penicillin treatments and other drugs had to be substituted with an average of 7.77 treatments required. The average number of treatments for the series of 34 was 5.13 compared with an average of 3.76 treatments for a control series of 461 cases treated with commonly used drugs. Thus, when penicillin-sensitive organisms are present results with penicillin therapy are very favorable, but when resistant organisms are present, results are definitely inferior to those obtained with other drugs.

In Table II the effectiveness of penicillin in cases of Streptococcus anhemolyticus infections is compared with its effectiveness in cases of Streptococcus viridans infections. It will be noted that the results obtained very closely follow the pattern of penicillin sensitivity found "in vitro" by Crowley and Harner. Only 7 out of $18(38.88 \%)$ of Streptococcus anhemolyticus infections yielded to penicillin therapy, which compares with an "in vitro" sensitivity of $12.5 \%$ while 12 out of $17(70.58 \%)$ of Streptococcus viridans infections yielded to penicillin therapy compared to an "in vitro" sensitivity of $89.1 \%$. Thus, there was a close

\footnotetext{
${ }^{2}$ Crowley, M. and Harner, V., J. D. Res. 26: 399, 1947 (this issue).
} 
correlation between penicillin sensitivity as determined in the laboratory and the clinical results.

Table III compares the effectiveness of penicillin with some other commonly used root canal antiseptics on the basis of the number of cases becoming sterile

TABLE I

Summary of penicillin study

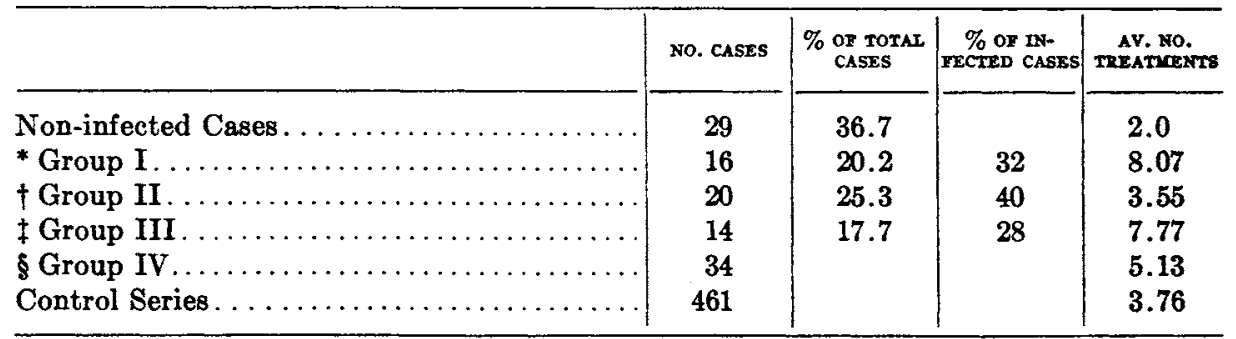

* Group I-Cases eliminated from consideration because of accidental contamination. † Group II-Cases which yielded to penicillin therapy.

$\ddagger$ Group III-Cases which did not yield to penicillin therapy, but responded to other drugs.

8 Group IV-Groups II and III combined.

TABLE II

Bacteriology and penicillin effectiveness

\begin{tabular}{|c|c|c|c|c|}
\hline & No. CASES & $\underset{\substack{\text { CASES } \\
\text { OF INIECTED }}}{\text { of }}$ & $\begin{array}{l}\text { No. YIEIDING To } \\
\text { PENICEIIIN }\end{array}$ & $\begin{array}{l}\text { \% or IN VITRO } \\
\text { SENSITIVITY }\end{array}$ \\
\hline $\begin{array}{l}\text { Strep. anhem } \ldots \ldots \ldots \ldots \ldots \ldots \ldots \\
\text { Strep. viridans................... }\end{array}$ & $\begin{array}{l}* 18 \\
17\end{array}$ & $\begin{array}{l}* 52.94 \\
50\end{array}$ & $\begin{aligned} 7 & (38.88 \%) \\
12 & (70.58 \%)\end{aligned}$ & $\begin{array}{l}\dagger 12.5 \\
\ddagger 89.1\end{array}$ \\
\hline
\end{tabular}

* One case was a mixed Strep. viridans and anhemolyticus infection.

$\dagger$ Based on laboratory tests of 88 strains isolated from root canals.

$\ddagger$ Based on laboratory tests of 82 strains isolated from root canals.

TABLE III

Comparison of effectiveness of penicillin with other commonly used antiseptics

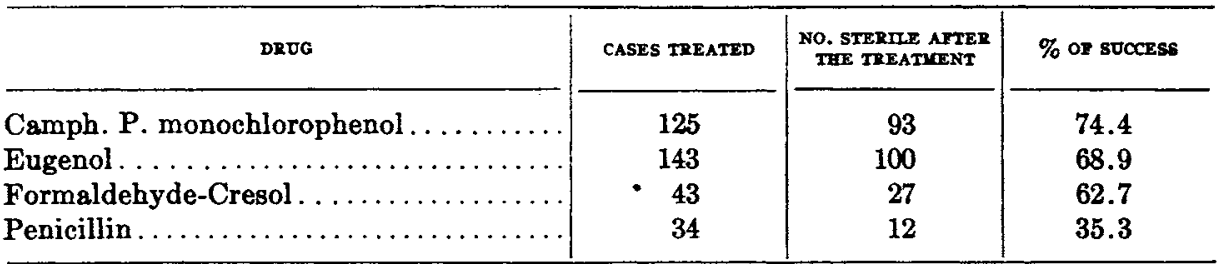

after one treatment. It will be noted that penicillin compared unfavorably with camphorated paramonochlorophenol, eugenol, and formaldehyde-cresol solution. All cases were treated by exactly the same routine except for the different drugs which were sealed in the canal.

The possibility that penicillin-sensitive strains of organisms might become 
resistant after exposure to several penicillin treatments was considered. However, there was no evidence in this study that such resistance was produced. In

TABLE IV

Typical cases of penicillin-resistant infections

\begin{tabular}{|c|c|c|c|c|c|}
\hline PATIRNT & $\begin{array}{l}\text { TOOTH } \\
\text { No. }\end{array}$ & RADIOLOGY & DRUG USED & BACTERYOLGY & $\begin{array}{l}\text { PENICILLIN } \\
\text { SENSITYV } \\
\text { ITY }\end{array}$ \\
\hline D. T. & 5 & Normal & $\begin{array}{lc}2-6-47 & \text { Penicillin } \\
2-10-47 & \text { "، } \\
2-12-47 & \text { "، } \\
2-14-47 & \text { "، } \\
2-17-47 & \text { c.p.m.cl.phe. } \\
2-19-47 & \text { "، } \\
2-21-47 & \text { ". }\end{array}$ & $\begin{array}{c}\text { Strep. anhem. } \\
\text { " } \\
\because \\
\text { " } \\
\text { " } \\
\text { No Growth } \\
\text { " }\end{array}$ & $\begin{array}{l}+ \\
+ \\
+ \\
+ \\
+\end{array}$ \\
\hline L. T. & 3 & Normal & $\begin{array}{l}2-25-47 \text { Penicillin } \\
2-28-47 \text { “" } \\
3-7-47 \\
3-14-47 \\
3-21-47 \text { c.p.m.chl.phe. } \\
3-24-47 \text { “" } \\
3-25-47 \text { Iod. Phe. } \\
3-28-47 \text { " " }\end{array}$ & $\begin{array}{c}\text { Strep. anhem. } \\
\text { " } \\
\text { " } \\
\text { " } \\
\text { " } \\
\text { No Growth } \\
\text { " }\end{array}$ & $\begin{array}{l}+ \\
+ \\
+ \\
+\end{array}$ \\
\hline
\end{tabular}

$+=$ Penicillin-resistant organism.

TABLE V

Cases of penicillin-sensitive infections

\begin{tabular}{|c|c|c|c|c|c|}
\hline PATIENT & $\begin{array}{c}\text { Toorr } \\
\text { No. }\end{array}$ & RADYOLOGY & DRUG USED & BACTERIOLOCY & \begin{tabular}{|c} 
PENICIL \\
IINS \\
SERSI- \\
TIVITY
\end{tabular} \\
\hline J.S. & 9 & $\begin{array}{c}\text { Chr. Prolif. } \\
\text { Periosteitis }\end{array}$ & $\begin{array}{l}3-3-47 \text { Penicillin } \\
3-6-47 \quad \text { "، plus } \\
3-8-47 \quad \text { " } \\
240,000 \text { u. I. M. } \\
3-10-47 \text { Penicillin } \\
3-15-47 \text { "“ } \\
3-17-47 \text { c.p.m.chl.phe. } \\
3-20-47 \quad \text { " } \\
3-22-47 \\
3-27-47\end{array}$ & $\begin{array}{l}\text { No culture } \\
\text { Strep. viridans } \\
\text { " " } \\
\text { No Growth } \\
\text { Strep. viridans } \\
\text { " " " } \\
\text { No Growth } \\
\text { " " }\end{array}$ & - \\
\hline L. P. & 4 & Normal & $\begin{array}{ll}2-10-47 & \text { Penicillin } \\
2-12-47 & \text { " } \\
2-14-47 & \text { " } \\
2-17-47 & \text { "، } \\
2-19-47 & \end{array}$ & $\begin{array}{l}\text { Strep, viridans } \\
\text { " " } \\
\text { " } \\
\text { No Growth } \\
"\end{array}$ & $\begin{array}{l}- \\
-\end{array}$ \\
\hline
\end{tabular}

- = Penicillin-sensitive organism.

only one instance did an organism established as penicillin-sensitive "in vitro" require more than 3 penicillin treatments to obtain the first negative culture. 
This strain was exposed to 5 topical penicillin treatments plus $240,000 \mathrm{u}$. intramuscularly, but was still penicillin-sensitive. (Table V). In short organisms which were penicillin-sensitive at the start of treatment remained sensitive and, conversely, organisms which were penicillin-resistant at the start of treatment remained resistant. Typical cases are shown in Tables IV and V.

\section{CONCLUSIONS}

Since the laboratory phase of this study has shown a high incidence of penicillin-resistant organisms to be found in root canal and periapical infections and since clinical results have closely paralleled the laboratory findings, it is concluded that penicillin is not a satisfactory drug for the treatment of such infections. It is obvious that the practicing dentist will have neither the time nor the equipment to determine penicillin-sensitivity and when resistant organisms are encountered much valuable time will be lost if penicillin is used routinely. However, further studies of the newer antibiotics and of possible combinations of penicillin with them, would seem indicated.

The authors are indebted to Bristol Laboratories, Syracuse, New York, for the penicillin used in this study and to Schenley Laboratories, New York, N. Y. for the penicillinase.

\section{REFERENCES}

1. BENDER, I. B., J. A. D. A., 34: 99, 1947.

2. Adasu, F. R., D. Items Interest, 66: 1147, 1944.

3. Stewart, G. G., J. A. D. A., 33: 1281, 1946.

4. Potkin, N. N., J. A. D. A., 34: 459, 1947.

5. Buchbinder, M., J. A. D. A., 34: 108, 1947.

6. DunN, L. J., J. 2nd Dist. D. Soc. (N.Y.), $31: 255,1945$.

7. Grossman, L. I., J. Endodontia, 1: 30, 1946.

8. Idem, Root Canal Therapy. 2nd ed. (Philadelphia, Lea and Febiger: 1946).

9. Pear, J. R., J. Endodontia, 1: 32, 1946.

10. Kakavas, J. C. ANd Scott, E. G., Science, 104: 327, 1946. 